\title{
Prediction of Moisture Content of Natural Gases Using Simple Arrhenius-type Function
}

Research Article

\author{
Alireza Bahadori* \\ School of Chemical and Petroleum Engineering, \\ Curtin University, GPO Box U1987, \\ Perth, WA, 6845 Australia
}

Received 22 January 2011 ; accepted 16 February 2011

\begin{abstract}
Natural gas extracted from underground reservoirs is saturated with water. The accurate prediction of moisture content in natural gas is extremely important. The presence of water vapor can lead to potentially disastrous consequences. The lifetime of a pipeline is governed by the rate at which corrosion occurs, which is directly linked to the available moisture in the gas resulting in oxidation. In addition, the formation of hydrates due to presence of water in natural gas can lead to safety hazards to production/transportation systems and to substantial economic risks. In this paper, an attempt has been made to develop an easy-to-use Arrhenius-type asymptotic exponential function combined with the Vandermonde matrix to arrive at an appropriate estimation of saturated water content of sour natural gases for pressures up to $69000 \mathrm{kPa}$ and the temperature range between 20 to $180^{\circ} \mathrm{C}$. Percent average absolute deviation of the proposed method is found to be around $2 \%$, demonstrating the excellent performance of the developed predictive tool. The tool will be of great practical value for chemical and petroleum engineers to have a quick check on the water content of sour natural gases at various temperatures and pressures without performing any experimental measurements.
\end{abstract}

Keywords: Natural gas $\bullet$ water content $\bullet$ Arrhenius function $\bullet$ predictive tool $\bullet$ Vandemonde matrix $\bullet$ Matlab program (c) Versita Sp. z o.o.

\section{Introduction}

Moisture removal is a key stage of natural gas conditioning and processing prior to sale and its efficiency is important in order to satisfy fiscal contractual obligations and to ensure that the gas is safe to transport and contains the right properties for subsequent use [1]. When the gas is produced there is a simultaneous production of water as well. Some of this water is produced water from

*E-mail: alireza.bahadori@postgrad.curtin.edu.au, Tel: +61 89266 1782, Fax: +6189266 2681 the reservoir directly [2]. In the transmission of natural gas, further condensation of water is problematic. It can increase pressure drop in the line, often leading to corrosion problems and gas hydrate formation $[1,2]$ which can reduce pipeline flow capacities, blockages and potential damage to process filters, valves and compressors. Such hydrates are caused by the combination of excessive water vapor with liquid hydrocarbons, which may condense out of the gas in the course of transmission to form emulsions that, under process pressure conditions, are solid masses. There are numerous methods available for determining water content of natural gases [3-8]. In some of these models the vapor pressure of pure water is required 
as an input. Poor estimates of the vapor pressure will lead to poor estimates of the water content [2]. For example Sharma and Campbell [9] proposed a method for calculating the water content of natural gas. This method is rather difficult to use for hand calculations. Firstly, it requires the compressibility factor of the gas mixture. Secondly, it requires the fugacity of pure water at system conditions. The chart given to estimate this value is only valid for temperatures between $80^{\circ} \mathrm{F}\left(26.7^{\circ} \mathrm{C}\right)$ and $160^{\circ} \mathrm{F}\left(71.1^{\circ} \mathrm{C}\right)$ and for pressure less than 2000 psia (13800 kPa). This method requires three fugacity calculations for a single water content estimate.

McKetta and Wehe [10] published a chart for estimating the water content of sweet natural gas. This chart has been modified slightly over the years and has been reproduced in many publications, most notably the Gas Processors and Suppliers Association (GPSA) Engineering Data Book [11]. To obtain the values in this study, the original chart was photo enlarged to double its original size. Even so, it is difficult to read the chart to an accuracy of more than two significant figures [2]. The McKetta-Wehe chart is not applicable to sour gas, and there have been corrections proposed to make the chart applicable to these systems $[12,13]$. In addition, Kobayashi et al. [7] presented a correlation for the curves plotted in the McKetta-Wehe chart. Their equation is quite complicated and it is only applicable for temperatures up to $120^{\circ} \mathrm{F}\left(48.9^{\circ} \mathrm{C}\right)$ and to 2000 psia (13800 kPa) [14].

For these above-mentioned reasons, the water content of sour natural gases is an important engineering consideration. Therefore, there is an essential need to develop a practical, reliable and easy-to-use method for practice engineers for the rapid estimation of the water content of sour natural gases to ensure successful, efficient and reliable gas transmission and processing plant operations.

\section{Development of the predic- tive tool}

Developing new predictive tools to minimize the complex and time-consuming calculation steps for estimating sour gas water content is an essential need. As most simulations require simultaneous iterative solutions of many nonlinear and highly coupled sets of equations, it is apparent that a mathematically compact, simple and reasonably accurate equations containing few tuned coefficients would be preferable for computationally intensive simulations [15]. In fact, the development of practical correlations by a small modification to the well-known Vogel-Tammann-Fulcher (VTF) (Vogel [16], Tammann and Hesse [17], Fulcher [18]) and Arrehnius [19] equation was the primary motivation for the present paper, which nevertheless, yields predictive tools with accuracy comparable to that of the existing rigorous simulations. The present study discusses the formulation of such a novel and simple predictive tool which can be of significant importance to engineers to accurately estimate sour gas water content. Matlab [20] technical computing language and Vandermonde matrix can be used to adjust the parameters of predictive tool.

The primary purpose of the present study is to accurately estimate the water content of sour gases (W) as a function of temperature and pseudo $\mathrm{H}_{2} \mathrm{~S}$ mole fraction (y). This is done by a simple predictive tool using an Arrhenius-type asymptotic exponential function with a small modification of the Vogel-Tammann-Fulcher (VTF) equation (Vogel [16], Tammann and Hesse [17], Fulcher [18]) combined with the Vandermonde matrix and using Matlab technical computing language [15]. This is important as such an accurate and mathematically simple correlation the water content of sour gases (W) is required frequently for quick engineering calculations to avoid the additional computational burden of complicated calculations. The Vogel-Tammann-Fulcher (VTF) equation (Vogel [16], Tammann and Hesse [17], Fulcher [18]) is an asymptotic exponential function that is given in the following general form [21]:

$$
\ln f=\ln \left(f_{c}\right)-\frac{E}{R\left(T-T_{c}\right)}
$$

In equation $1, f$ is a properly defined temperaturedependent parameter, the units for which are determined individually for a certain property; $f_{c}$ is a pre-exponential coefficient, having the same unit of the property of interest; $T$ and $T_{c}$ are the actual temperature and the characteristic-limit temperature, respectively (both given in degrees Kelvin); $E$ is referenced as the activation energy of the process causing parameter variation (given in units of $\mathrm{J} / \mathrm{kmol}$ ); and $R$ is the universal gas constant (R) $8.314 \mathrm{~J} /(\mathrm{kmol} \mathrm{K}))$. A special case of the VogelTammann-Fulcher (VTF) equation (Vogel [16], Tammann and Hesse [17], Fulcher [18]) for $T_{c}=0$ is the well-known Arrhenius [19] equation.

For the purpose of this application which involves the correlation of density and vapor pressure of aqueous methanol or glycols solutions as a function of temperature, the Vogel-Tammann-Fulcher (VTF) equation (Vogel [16], Tammann and Hesse, [17], Fulcher [18]) has been modified in the following form by adding second-order and third order terms $[15,21]$.

$$
\ln f=\ln f_{c}+\frac{b}{T-T_{c}}+\frac{c}{\left(T-T_{c}\right)^{2}}+\frac{d}{\left(T-T_{c}\right)^{3}}
$$


In equation $2, \mathrm{~T}_{c}$ has been considered zero to convert equation 2 to the well-known Arrhenius [19] equation type.

$$
\ln f=\ln f_{c}+\frac{b}{T}+\frac{c}{T^{2}}+\frac{d}{T^{3}}
$$

The required data to develop this correlation includes the reported data [11], for the water content of sour gases (W) [11] as a function of temperature and pseudo $\mathrm{H}_{2} \mathrm{~S}$ mole fraction $(y)$. The following methodology using Vandermonde matrix and Matlab [20] technical computing language have been applied to develop this correlation.

\subsection{Vandermonde matrix}

Vandermonde matrix is a matrix with the terms of a geometric progression in each row, i.e., an $m \times n$ matrix [22].

$$
V=\left[\begin{array}{ccccc}
1 & \alpha_{1} & \alpha_{1}^{2} & \ldots & \alpha_{1}^{n-1} \\
1 & \alpha_{2} & \alpha_{2}^{2} & \ldots & \alpha_{2}^{n-1} \\
1 & \alpha_{3} & \alpha_{3}^{2} & \ldots & \alpha_{3}^{n-1} \\
\vdots & \vdots & \vdots & \ddots & \vdots \\
1 & \alpha_{m} & \alpha_{m}^{2} & \ldots & \alpha_{m}^{n-1}
\end{array}\right]
$$

Or

$$
V_{i, j}=\alpha_{i}^{j-1}
$$

For all indices $i$ and $j$. The determinant of a square Vandermonde matrix (where $m=n$ ) can be expressed as [22]:

$$
\operatorname{det}(V)=\prod_{1 \leq i<j \leq n}\left(\alpha_{j}-\alpha_{i}\right)
$$

The Vandermonde matrix evaluates a polynomial at a set of points; formally, it transforms coefficients of a polynomial $a_{0}+a_{1} x+a_{2} x^{2}+\ldots+a_{n-1} x^{n-1}$ to the values the polynomial takes at the point's $\alpha_{i}$. The non-vanishing of the Vandermonde determinant for distinct points $\alpha_{i}$ shows that, for distinct points, the map from coefficients to values at those points is a one-to-one correspondence, and thus that the polynomial interpolation problem is solvable with unique solution; this result is called the unisolvence theorem [23].

Thus, these are useful in polynomial interpolation, since solving the system of linear equations $V u=y$ for $u$ with $V$ an $m \times n$ Vandermonde matrix is equivalent to finding the coefficients $\mathrm{u}_{j}$ of the polynomial(s) [23]

$$
P(x)=\sum_{j=0}^{n-1} u_{j} x^{j}
$$

of degree $\leq n-1$ which has (have) the property:

$$
P\left(\alpha_{i}\right)=y_{i} \quad \text { for } \quad i=1, \ldots, m \text {. }
$$

The Vandermonde matrix can easily be inverted in terms of Lagrange basis polynomials: each column is the coefficients of the Lagrange basis polynomial, with terms in increasing order going down. The resulting solution to the interpolation problem is called the Lagrange polynomial [23].

\subsection{Approach to Developing the Predic- tive tool}

The required data to develop this correlation includes the reported data for water content of sour gases (W) [11] as well as temperature and pseudo $\mathrm{H}_{2} \mathrm{~S}$ mole fraction (y). Equation 9 provides pseudo $\mathrm{H}_{2} \mathrm{~S}$ mole fraction (y) as a function of $\mathrm{CO}_{2}$ and $\mathrm{H}_{2} \mathrm{~S}$ mole fractions. The water content of sour natural gas is predicted rapidly by proposing a novel correlation. The following methodology using Matlab [20] and Vandermoncde matrix has been applied to develop this predictive tool.

For a given pressure, water content of sour gases (W) are first correlated as a function of temperature for various reported pseudo $\mathrm{H}_{2} \mathrm{~S}$ mole fraction (y). Then, the calculated coefficients for these polynomials are correlated as a function of pseudo $\mathrm{H}_{2} \mathrm{~S}$ mole fraction (y). The derived polynomials are applied to calculate new coefficients for equation (10) to predict water content of sour gases (W). Table 1 shows the tuned coefficients for equations (11) to (14) for pressure at 6900, 14000, 21000, 41000 and 69000 kPa (abs).

$$
\begin{gathered}
y=y_{\mathrm{H}_{2} S}+0.75 \times y_{\mathrm{CO}_{2}} \\
\ln (W)=a+\frac{b}{T}+\frac{c}{T^{2}}+\frac{d}{T^{3}}
\end{gathered}
$$

Where:

$$
\begin{aligned}
& a=A_{1}+B_{1} y+C_{1} y^{2}+D_{1} y^{3} \\
& b=A_{2}+B_{2} y+C_{2} y^{2}+D_{2} y^{3} \\
& c=A_{3}+B_{3} y+C_{3} y^{2}+D_{3} y^{3} \\
& d=A_{4}+B_{4} y+C_{4} y^{2}+D_{4} y^{3} \\
& W=W_{1}+\left(P-P_{1}\right) \frac{\left(W_{2}-W_{1}\right)}{\left(P_{2}-P_{1}\right)}
\end{aligned}
$$

In brief, the following steps are repeated to tune the correlation's coefficients. 
Table 1. Tuned coefficients used in equation 11-14 to correlate water content as a function of temperature at $6900,14000 \mathrm{kPa}(\mathrm{abs}), 21000$, 41000 and $69000 \mathrm{kPa}$ (abs).

\begin{tabular}{|c|c|c|c|c|c|}
\hline Value for $69000 \mathrm{kPa}$ & Value for $41000 \mathrm{kPa}$ & Value for $21000 \mathrm{kPa}$ & Value for $14000 \mathrm{kPa}$ & Value for $6900 \mathrm{kPa}$ & Coef \\
\hline $1.1487249695996 \times 10^{1}$ & $1.748930534066 \times 10^{1}$ & 8.8752257764411 & $1.8110838211653 \times 10^{1}$ & -8.6992897364476 & $\overline{A_{1}}$ \\
\hline $9614239 \times 10^{2}$ & $-6.6857234321439 \times 10^{1}$ & $5865547 \times 10^{1}$ & $27198229 \times 10^{1}$ & $\times 10^{1}$ & $B_{1}$ \\
\hline-1.28 & 1.07901133238 & $10^{2}$ & 1.68 & 3.13152615 & $c_{1}$ \\
\hline 2.115 & -2.27 & $10^{2}$ & -2.6948 & 0 & $D_{1}$ \\
\hline-2.654 & $-8.7901042066063 \times 10^{3}$ & $5.1776138075660 \times 10^{2}$ & $216 \times 10^{3}$ & $10^{4}$ & $A_{2}$ \\
\hline$\times 10^{5}$ & 6.67819041 & $-8.7971995837776 \times 10^{4}$ & $3.0551218745808 \times 10^{4}$ & $4.9646614809644 \times 10^{4}$ & $B_{2}$ \\
\hline 1.46985 & $-1.176159078161 \times 10^{6}$ & $-8.3722203514478 \times 10^{4}$ & $-1.7056837565438 \times 10^{5}$ & $-3.4189493136275 \times 10^{5}$ & $C_{2}$ \\
\hline-2.40 & $2.498247990701 \times 10^{6}$ & $6.8032176760827 \times 10^{5}$ & 2.811526034076 & 0 & $D_{2}$ \\
\hline-7.5258 & $97 \times 10^{6}$ & -1.66462351 & $1.385122323083 \times 10^{6}$ & -8.428384598816 & $A_{3}$ \\
\hline $8.1236523831462 \times 10^{7}$ & -2.1776 & $3.5036420983709 \times 10^{7}$ & $-8.6675428997521 \times 10^{6}$ & $-1.7339466157663 \times 10^{7}$ & $B_{3}$ \\
\hline$-5.5361784748092 \times 10^{8}$ & $4.2432245600508 \times 10^{8}$ & $1.833030185193 \times 10^{7}$ & $5.5966077952265 \times 10^{7}$ & $1.2339127230272 \times 10^{8}$ & $C_{3}$ \\
\hline $8.9969938341627 \times 10^{8}$ & $-9.078369462879 \times 10^{8}$ & $-2.3174062571704 \times 10^{8}$ & $-9.624968254877 \times 10^{7}$ & 0 & $D_{3}$ \\
\hline $1.1064336815477 \times 10^{8}$ & $-1.495941594688 \times 10^{8}$ & $1.7742319902892 \times 10^{8}$ & $-1.636288455096 \times 10^{8}$ & $9.3484127541312 \times 10^{8}$ & $A_{4}$ \\
\hline$-1.0161844621207 \times 10^{10}$ & $2.4252810682628 \times 10^{9}$ & -4.493253811308 & $7.9328177772919 \times 10^{8}$ & $2.0283228863636 \times 10^{9}$ & $B_{4}$ \\
\hline $6.8764136066843 \times 10^{10}$ & $92989058 \times 10^{10}$ & -6.48 & $-5.955397398353 \times 10^{9}$ & $-1.4729685977716 \times 10^{10}$ & $C_{4}$ \\
\hline$-1.1126881236117 \times 10^{11}$ & $1.0921229873138 \times 10^{11}$ & $2.5791018846089 \times 10^{10}$ & $1.086941710694 \times 10^{10}$ & 0 & $D_{4}$ \\
\hline
\end{tabular}

1. Correlate the water content of sour gases (W) as a function of temperature for the selected pseudo $\mathrm{H}_{2} \mathrm{~S}$ mole fractions $(y)$.

2. Repeat steps 2 and 3 for other data and other pseudo $\mathrm{H}_{2} \mathrm{~S}$ mole fractions (y).

3. Correlate corresponding polynomial coefficients, which were obtained for different temperatures versus pseudo $\mathrm{H}_{2} \mathrm{~S}$ mole fraction $(y), a=f(y), b=$ $f(y), c=f(y), d=f(y)$ [see equations (11)-(14)].

4. Calculate the water content of sour gases (W) as a function of temperature and pseudo $\mathrm{H}_{2} \mathrm{~S}$ mole fraction from equations (10) and (14), respectively.

5. Calculate water content of sour natural gas using simple interpolation formula (equation 15) to various pressures.

6. The water content of sour gases at low pressures is approximately independent of composition, so equation 16 and Table 2 are suggested to calculate water content at $2100 \mathrm{kPa}$ (abs).

$$
\ln (W)=\alpha+\frac{\beta}{T}+\frac{\gamma}{T^{2}}+\frac{\theta}{T^{3}}
$$

Equations 9-16 present the developed tool for predicting water content of sour natural gases, as a function of temperature, pseudo $\mathrm{H}_{2} \mathrm{~S}$ mole fractions and pressures. The tuned coefficients are also given in Table 1 can be
Table 2. Tuned coefficients used in equation 16 to correlate water content as a function of temperature at $2100 \mathrm{kPa}(\mathrm{abs})$.

\begin{tabular}{cc}
\hline Coefficients & Value \\
\hline \hline$\alpha$ & $-1.7726834385506 \times 10^{1}$ \\
$\beta$ & $3.0306586238333 \times 10^{4}$ \\
$\gamma$ & $-1.1989223586817 \times 10^{7}$ \\
$\theta$ & $1.3598977939352 \times 10^{9}$ \\
\hline
\end{tabular}

also retuned if more accurate data are available in the future.

The predictive tool proposed in is simple and has an unique expression which is non-existent in the literature. In addition, logarithmic function is selected to develop the correlation, as these functions are smooth and wellbehaved (i.e. smooth and non-oscillatory) equations which should allow for more accurate predictions [15].

\section{Results}

Figure 1 shows the developed Matlab-based predictive tool. Figures 2 to 6 show the obtained results of the new proposed predictive tool for predicting the water content of sour natural gases at 6900, 14000, 21000, 41000 and $69000 \mathrm{kPa}$ (abs) respectively. As shown, the obtained results show good agreement with the reported data. Table 3 shows that the proposed predictive tool has good agreement with the reported data [11] and the average absolute deviation is around $2 \%$. 
Table 3. Comparison of obtained results of new proposed predictive tool for predicting water content of sour gases with the reported data [11].

\begin{tabular}{|c|c|c|c|c|c|}
\hline $\begin{array}{c}\text { Pressure } \\
\mathrm{kPa}\end{array}$ & $\begin{array}{c}\text { Temperature } \\
{ }^{\circ} \mathrm{C}\end{array}$ & $\begin{array}{c}\text { Pseudo } \mathrm{H}_{2} \mathrm{~S} \\
\text { mole fraction }(\mathrm{y}) \\
\end{array}$ & $\begin{array}{c}\text { Calculated water content } \\
\frac{m g}{\mathrm{sm}} \\
\end{array}$ & $\begin{array}{l}\text { Reported water content, [11] } \\
\qquad \frac{m g}{\mathrm{sm}^{3}} \\
\end{array}$ & $\begin{array}{l}\text { Absolute deviation percent } \\
\end{array}$ \\
\hline 6900 & 32 & 0 & 0.6185 & 0.6 & 3.08 \\
\hline 6900 & 66 & 20 & 3.9133 & 4 & 2.16 \\
\hline 6900 & 132 & 40 & 40.0084 & 40 & 0.21 \\
\hline 14000 & 30 & 0 & 0.3919 & 0.4 & 2.02 \\
\hline 14000 & 44 & 10 & 0.9144 & 0.9 & 1.6 \\
\hline 14000 & 77 & 20 & 4.0774 & 4 & 1.93 \\
\hline 14000 & 128 & 30 & 28.3998 & 30 & 5.33 \\
\hline 14000 & 169 & 40 & 57.7452 & 60 & 3.90 \\
\hline 21000 & 38 & 0 & 0.4653 & 0.5 & 6.94 \\
\hline 21000 & 50 & 10 & 1.0476 & 1 & 4.76 \\
\hline 21000 & 98 & 20 & 7.0879 & 7 & 1.25 \\
\hline 21000 & 103 & 30 & 9.2284 & 9 & 2.53 \\
\hline 21000 & 164 & 40 & 40.3141 & 40 & 0.78 \\
\hline 41000 & 32 & 0 & 0.29478 & 0.3 & 1.74 \\
\hline 41000 & 47 & 10 & 0.7782 & 0.8 & 2.72 \\
\hline 41000 & 86 & 20 & 3.9497 & 4 & 1.25 \\
\hline 41000 & 100 & 30 & 7.1196 & 7 & 1.70 \\
\hline 41000 & 158 & 40 & 30.0236 & 30 & 0.08 \\
\hline 69000 & 27 & 0 & 0.19827 & 0.2 & 0.87 \\
\hline 69000 & 48 & 10 & 0.705348 & 0.7 & 0.76 \\
\hline 69000 & 91 & 20 & 3.9686 & 4 & 0.78 \\
\hline 69000 & 109 & 30 & 8.07455 & 8 & 0.93 \\
\hline 69000 & 162 & 40 & 29.897 & 30 & 0.34 \\
\hline \multicolumn{5}{|c|}{ Average absolute deviation percent (AADP) } & 2.07 \\
\hline
\end{tabular}

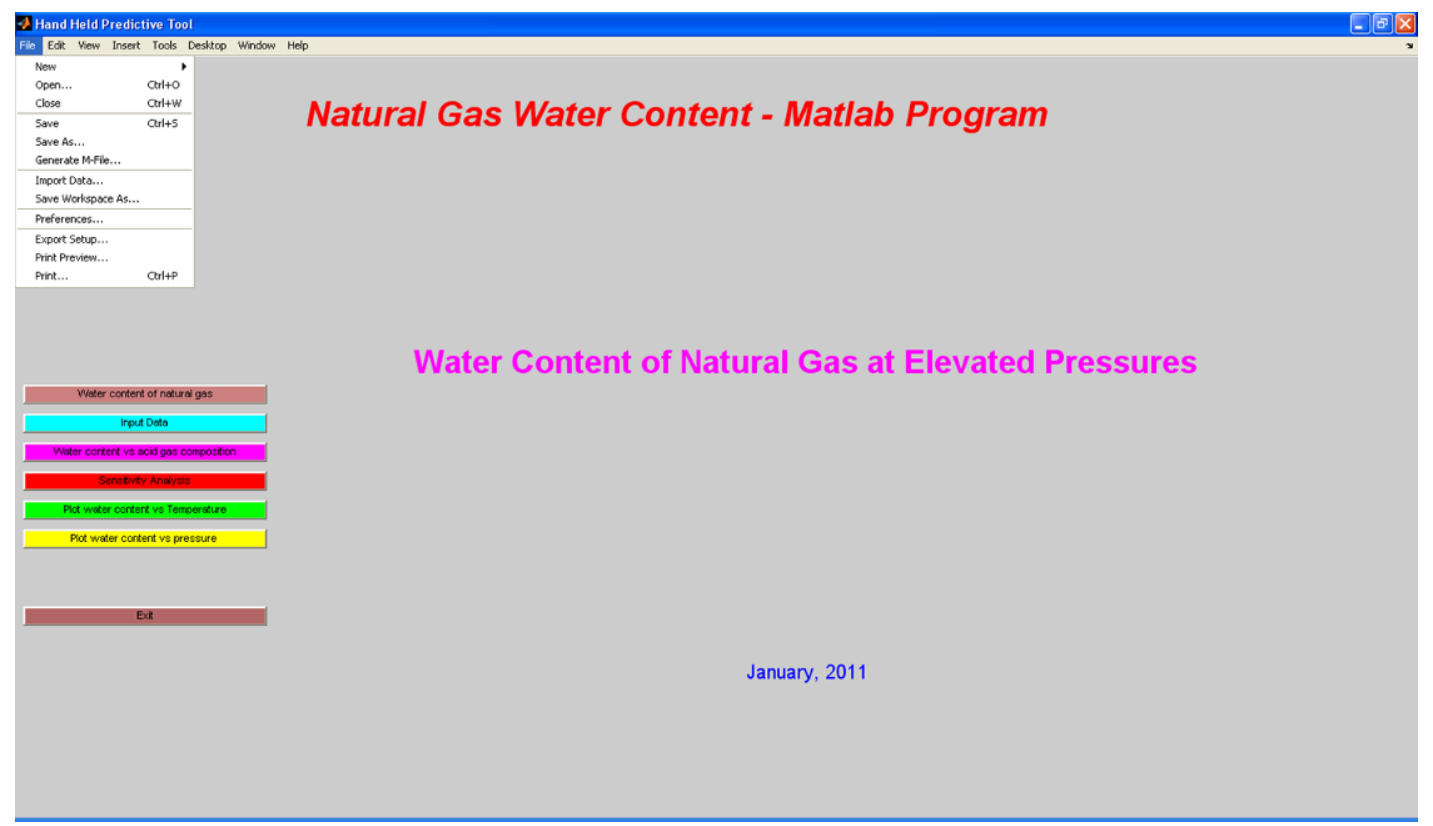

Figure 1. Developed Matlab-based [15] predictive tool for calculating sour gas water content. 


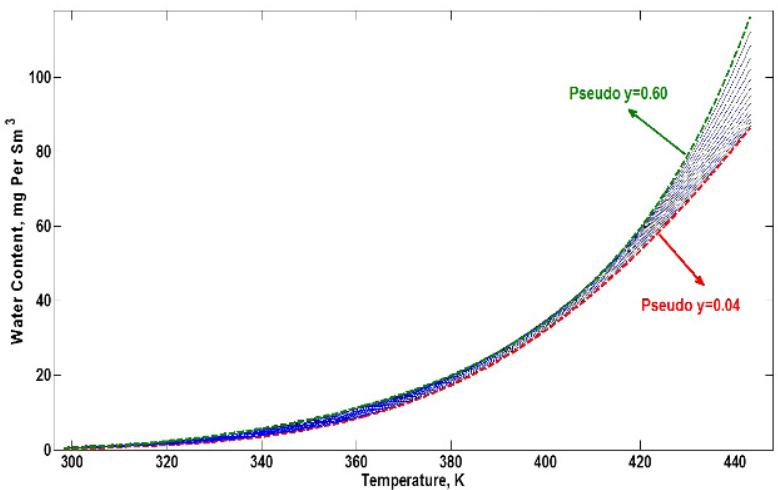

Figure 2. Performance of proposed predictive tool for estimation of water content of sour natural gases at $6900 \mathrm{kPa}(\mathrm{abs})$.

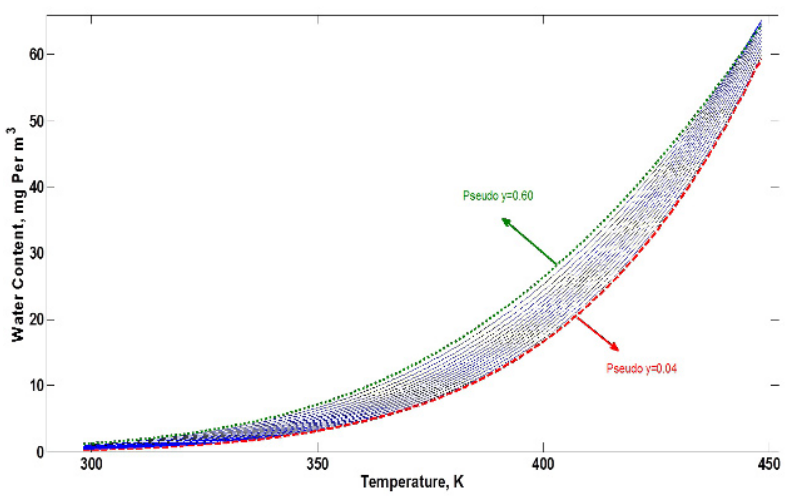

Figure 3. Prediction of water content of sour natural gases and acid gas mixtures at $14000 \mathrm{kPa}$ (abs).

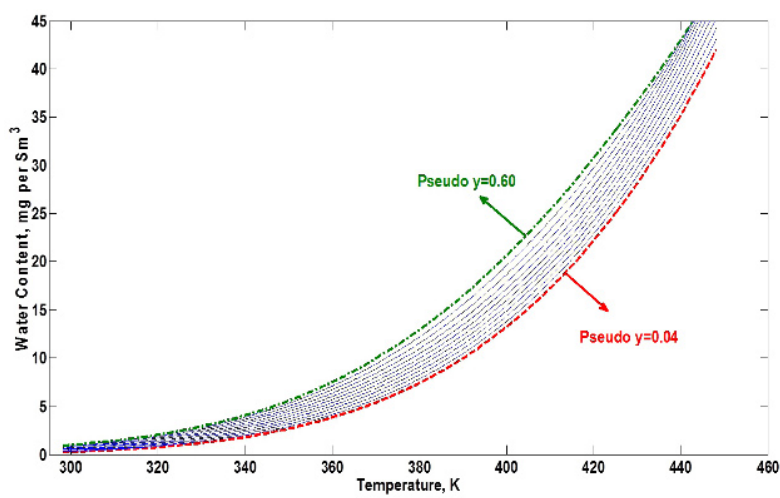

Figure 4. Prediction of water content of sour natural gases and acid gas mixtures at $21000 \mathrm{kPa}$ (abs).

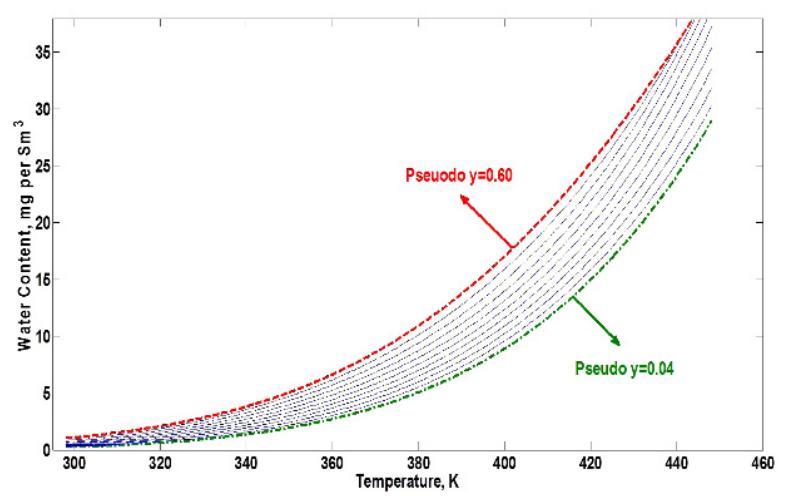

Figure 5. Prediction of water content of sour natural gases and acid gas mixtures at $41000 \mathrm{kPa}$ (abs).

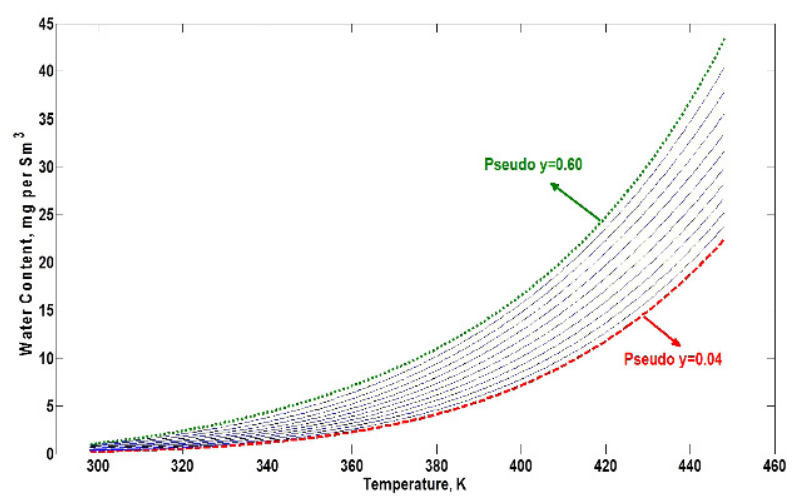

Figure 6. Prediction of water content of sour natural gases and acid gas mixtures at $69000 \mathrm{kPa}$ (abs).

The proposed simple method covers water content for temperatures range between $25-175^{\circ} \mathrm{C}$, and pseudo $\mathrm{H}_{2} \mathrm{~S}$ mole fraction up to 0.45 as well as pressure up to 69000 kPa (abs). Sample calculations shown here clearly demonstrate the simplicity of the proposed predictive tool and the benefits associated with such empirical estimations. The approach is of practical significance for natural gas processing industries and gas reservoir engineering in terms of assessing operational issues. In particular, the proposed correlation gives an advance indication of key parameters which could potentially enable practice engineers to take appropriate remedial measures in the design of facilities for natural gas production, transmission, and processing. 


\subsection{Sample calculation for practice engi- neers}

Determine the saturated water content of a mixture containing $80 \% \mathrm{CH}_{4}$ and $20 \% \mathrm{CO}_{2}$ at $70^{\circ} \mathrm{C}$ and 13800 kPa (abs).

Sample solution:

$y=y_{\mathrm{H}_{2} \mathrm{~S}}+0.75 \times y_{\mathrm{CO}_{2}}=0+0.75(0.2)=0.15$ (from equation 9).

$a=-8.69845264$ (from equation 11)

$b=1.9843321663 \times 10^{4}($ from equation 12$)$

$c=-8.253000895 \times 10^{6}($ from equation 13$)$

$d=9.0767177386 \times 10^{8}($ from equation 15$)$

$4.4993 \frac{\mathrm{mg}}{\mathrm{Sm}^{3}}$ at $6900 \mathrm{kPa}$. (from equation 10)

Now, repeat the calculations for pressure $=14000 \mathrm{kPa}$

$a=2.276836397 \times 10^{1}$ (from equation 11)

$b=-1.44306367582 \times 10^{4}($ from equation 12)

$c=3.776501918013 \times 10^{6}$ (from equation 13)

$d=-4.728356771532 \times 10^{8}$ (from equation 14)

$2.95842 \frac{\mathrm{mg}}{\mathrm{Sm}^{3}}$ at $14000 \mathrm{kPa}$. (from equation 10)

After interpolation, the water content of natural gas at $13800 \mathrm{kPa}$ will be:

$W=2.95842+(13800-14000)(4.4993-$ $2.95842) /(6900-14000)=2.99 \frac{\mathrm{mg}}{\mathrm{Sm}^{3}}$ (from equation 15)

This is a classic example showing how the information evolving out of the proposed predictive tool can be used to understand and estimate the water content of sour gases (W). The proposed tool is easy to use which employs simple algebraic equations and can be solved by a simple calculator quickly by any water practitioner without going into the complicated principles of thermodynamics and associated expressions.

\section{Conclusions}

Presented in this paper, a simple-to-use predictive tool for accurate estimation of water content of sour natural gas mixtures containing up to 40 mole percent acid gas components was developed. Predicted results show good agreement with the reported data, wherein the new developed method works for pressures up to $69000 \mathrm{kPa}$ (abs), temperatures from 25 to $180{ }^{\circ} \mathrm{C}$ and pseudo $\mathrm{H}_{2} \mathrm{~S}$ mole fractions up to 0.4 . The proposed correlation has excellent association with the reported data. Estimations from the proposed tool have been compared with reported data and found good agreement with average absolute deviation being less than $2.1 \%$. The proposed tool appears to be superior owing to its accuracy and simple background, wherein the relevant coefficients can be retuned quickly if new and more accurate data are available in the future. The example shown for the benefit of natural gas practitioners clearly demonstrates the usefulness of the proposed tool for the practice engineers. It is expected that our efforts in this investigation will pave the way by arriving at an accurate measure of the water content of sour gases at various conditions which can be used by the gas processing industries personnel for monitoring the operational parameters periodically in the design of facilities for the natural gas production, transmission, and processing.

\subsection{Nomenclature}

A: Tuned coefficient

B: Tuned coefficient

C: Tuned coefficient

D: Tuned coefficient

$E$ : The activation energy of the process causing parameter variation $(\mathrm{J} / \mathrm{kmol})$,

$f$ : properly defined temperature-dependent parameter, the units for which are determined individually for a certain property.

$f_{c}$ : pre-exponential coefficient, having the same unit of the property of interest

$\mathrm{i}$ : index

$\mathrm{j}$ : index

$m$ : matrix row index for $m \times n$ matrix

$\mathrm{n}$ :matrix column index for $m \times n$ matrix

P: Pressure, kPa(abs) 
$R$ : Universal gas constant $(R) 8.314 \mathrm{~J} /(\mathrm{kmol} \mathrm{K}))$

T: Temperature, $\mathrm{K}$

$\mathrm{T}_{c}$ : Characteristic-limit temperature, $\mathrm{K}$

u: coefficient of polynomial

V: Vandermonde matrix

W: Sour Gas water content, mg/(Standard cubic meter)

$y$ :Pseudo $\mathrm{H}_{2} \mathrm{~S}$ mole fraction

$\mathrm{yCO}_{2}$ : Carbon dioxide mole fraction

$y_{\mathrm{H}_{2} \mathrm{~S}}$ :Hydrogen sulfide mole fraction

$y$ : Pseudo $\mathrm{H}_{2} \mathrm{~S}$ mole fraction

$\alpha$ : Matrix element

\section{References}

[1] Bukacek R.F., Equilibrium Moisture Content of Natural Gases, Research Bulletin 8. Institute of Gas Technology, Chicago, USA, 1955

[2] Carroll J. J., The water content of acid gas and sour gas from 100 to $220^{\circ} \mathrm{F}$ and pressures to 10000 psia, 81st Annual GPA Convention, March 11-13, Dallas, Texas, USA, 2002

[3] Kobayashi R., Katz D.L., Vapor-Liquid Equilibria for Binary Hydrocarbon-Water Systems, Ind. Eng. Chem., 45,1953, 440-451

[4] Olds R.H., Sage B.H., Lacey W.N., Phase Equilibria in Hydrocarbon Systems, Composition of Dew-Point Gas in Methane-Water System, Ind. Eng. Chem. 34, 1942, 1223-1227

[5] Lukacs J., Robinson D.B., Water Content of Sour Hydrocarbon Systems, Society of Petroleum Engineers Journal, 3, 1963, 293-297

[6] Gillespie P.C., Owens J.L., Wilson G.M., Sour Water Equilibria Extended to High Temperature and with Inerts Present, AIChE Winter National Meeting, Paper 34-b, Atlanta, GA, 11-14 March 1984

[7] Carroll J.J., Mather A.E., Phase Equilibrium in the System Water-Hydrogen Sulphide: Modelling the Phase Behaviour With an Equation of State, Canadian Journal of Chemical Engineering, 67, 1989, 9991003
[8] Wichert G.C., Wichert, E., New Charts Provide Accurate Estimations for Water Content of Sour Natural Gas, Oil \& Gas Journal, 101 (41), 2003, 64-66

[9] Sharma S., Campbell, J.M., Predict Natural-gas Water Content with Total Gas Usage, Oil \& Gas Journal, 67 (31), 1969, 136-137

[10] McKetta J.J., Wehe A.H., Use This Chart for Water Content of Natural Gases, Petroleum Refiner ( $\mathrm{Hy}-$ drocarbon Processing), 37 (8), 1958, 153

[11] GPSA Engineering Data Book, 12th Ed., Gas Processors Suppliers Association (GPSA), Tulsa, OK, USA, 2004

[12] Bahadori A,. Vuthaluru H.B., Mokhatab S., Rapid Estimation of Water Content of Sour Natural Gases, Journal of the Japan Petroleum Institute 52 (3) 2009,

[13] Bahadori A., Vuthaluru H.B., Mokhatab S., Method Accurately Predicts Water Content of Natural Gases, Journal of Energy Sources, Part A: Recovery, Utilization, and Environmental Effects, 31 (5), 2009, 754 760

[14] Kobayashi R., Song K.Y. , Sloan E.D., Phase Behaviour of Water/Hydrocarbon Systems in Bradley, H.B., (ed.), Petroleum Engineers Handbook, Society of Petroleum Engineers, Richardson, TX, 1987

[15] Bahadori A., Novel Predictive Tools for Oil, Gas and Chemical Industries, VDM Verlag Publishing, Saarbrücken, Germany 2011

[16] Vogel H. Das Temperatureabhängigkeitsgesetz der Viskosität von Flüssigkeiten, Phys. Z., 22 1921, 645646 (in German)

[17] Tammann G., Hesse W., Die Abhängigkeit der Viskosität von der Temperature bei unterkühlten Flüssigkeiten, Z. Anorg. Allg. Chem. 156, 1926, 245257 (in German)

[18] Fulcher G.S., Analysis of Recent Data of the Viscosity of Glasses, J. Am. Ceram. Soc., 8, 1925, 339-355

[19] Arrhenius S., Über die Reaktionsgeschwindigkeit der Inversion von Rohrzucker durch Saeuren, Z. Phys. Chem., 4, 1889 226-248 (in German)

[20] MATLAB software, Version 7.6.0.324, The MathWorks, Inc, MA, USA, 2008

[21] Civan F., Use exponential functions to correlate temperature dependence, Chemical Engineering Progress 104 (4), 2008, 46-52

[22] Fulton W., Harris, J., Representation theory. A first course, Graduate Texts in Mathematics, A basic course in algebraic topology,GTM 127, Springer, 1991

[23] Horn R.A., Johnson C.R., Topics in matrix analysis, Cambridge University Press. See Section 6.1, UK Mathematics, 129, New York: Springer-Verlag, USA 1991 